\title{
Chemopreventive effect of Indigofera linnaei extract against diethylnitrosamine induced hepatocarcinogenesis in rats
}

\author{
Raju Senthil Kumar ${ }^{\text {* }}$, Sekar Vinoth Kumar ${ }^{1}$, Balasubramanian Rajkapoor ${ }^{2}$, Narayanaperumal Pravin ${ }^{3}$, Dharmasivam \\ Mahendiran $^{4}$ \\ ${ }^{1}$ Natural Products Laboratory, Swamy Vivekanandha College of Pharmacy, Tiruchengode, Tamilnadu, India. \\ ${ }^{2}$ Department of Pharmacology, Faculty of Medicine, Sebha University, Sebha, Libya. \\ ${ }^{3}$ Department of Chemistry, Indian Institute of Technology Bombay, Powai, Mumbai, India. \\ ${ }^{4}$ Department of Chemistry, The New College, Chennai, India.
}

\begin{tabular}{l} 
ARTICLE INFO \\
\hline Article history: \\
Received on: 09/09/2016 \\
Revised on: 29/09/2016 \\
Accepted on: 12/10/2016 \\
Available online: $29 / 11 / 2016$ \\
\hline Key words: \\
Indigofera linnaei, \\
Diethylnitrosamine, Serum \\
hepatic parameters, Tumour \\
markers, Chemoprevention, \\
Phytochemicals.
\end{tabular}

\begin{abstract}
Indigofera linnaei Ali., has been widely used in folk medicine to treat inflammation, liver disorders and swelling of stomach. Earlier studies showed that methanolic extract of Indigofera linnaei (MEIL) possess antioxidant, free radical scavenging, antitumour, anti-inflammatory and analgesic activities but its effect on chemoprevention on chemical induced carcinogenesis have not been studied. Hence the present study is aimed to investigate chemopreventive efficacy of MEIL against diethylnitrosamine (DEN) induced phenobarbital promoted rat liver carcinoma model. Liver tumour was induced in rats by intraperitoneal administration of DEN (200 mg/kg). After two weeks, the carcinogenic effect was promoted by phenobarbital given through drinking water for 16 successive weeks. MEIL ( 200 and $400 \mathrm{mg} / \mathrm{kg} /$ day) and silymarin $(200 \mathrm{mg} / \mathrm{kg} / \mathrm{day}$ ) were administered orally for entire study period. After the experimental period, changes in body weight, liver weight, relative liver weight, tumour incidence, antioxidant, serum hepatic parameters, serum specific tumour markers, nucleic acid and protein content were analysed. MEIL treatment significantly increased the body weight, reduced the liver weight and tumour incidence, restored the altered serum hepatic parameters, down-regulated the serum tumour markers such as alpha fetoprotein, carcinoembryonic antigen, vasculoendothelial growth factor and tumor necrosis factor- $\alpha$. In addition, treatment with MEIL restored the antioxidant enzyme pool and significantly reduced the lipid peroxidation in carcinogen treated animals. MEIL treatment also reduced the elevated levels of nucleic acid levels and restored the protein content in liver tissues. The results suggested that MEIL would be a potent chemopreventive agent inhibiting chemically induced hepatic cancer.
\end{abstract}

\section{INTRODUCTION}

Hepatocellular carcinoma (HCC) is the fifth most common cancer and second leading cause of cancer mortality throughout the world (Jemal et al., 2011). HCC has been linked with diverse etiologies including chronic hepatitis $\mathrm{B}$ and $\mathrm{C}$ infection and alcohol consumption (Shih et al., 2009; Kumar et al., 2011). Due to high tolerance of liver, HCC is rarely detected at the early stage and treatment has a poor prognosis in most of

* Corresponding Author

Raju Senthil Kumar, Natural Products Laboratory, Swamy

Vivekanandha College of Pharmacy, Tiruchengode, Tamilnadu, India.

Email:thrisen@gmail.com the cases, making it a significant health problem (El-Serag and Rudolph, 2007). The relapse rates of HCC are also high and the survival rate of the patient with HCC has not improved much from the past few decades. Surgical removal, including transplantation, is currently the most effective treatment for this dreadful disease. Diethylnitrosamine (DEN) is a potent environment carcinogen belongs to nitrosamine class which is entered through food chain (Mittal et al., 2006). DEN is synthesized endogenously and found in occupational settings, tobacco smoke, processed meat, alcoholic beverages, agricultural chemicals, cosmetics and pharmaceutical substances. It is also produced from metabolism of certain drugs (Sivaramakrishnan et al., 2008). 
It causes proliferative, degenerative and cancerous lesions in liver. It can alkylate DNA molecule with itself being converted to highly reactive molecule by $\mathrm{CYP}_{450}$ dependent oxygenases and generates reactive oxygen species (ROS) causing oxidative stress. DEN forms alkyl DNA adducts which induces chromosomal abbreration, micronuclei and chromatid exchanges in the liver and these mutations induced by DEN are responsible for the development of liver cancer (Mandal et al., 2008; Jagadeesh et al., 2009).

The rat model of DEN induced hepatocellular carcinoma is considered as one of the most accepted and widely used experimental models to study the chemopreventive and chemotherapeutic potential of many drugs.

Chemopreventive substances are identified on the basis of their antimutagenic, anti-inflammatory and antioxidant properties capable of inhibiting proliferation and induction of apoptosis which are the important criteria for their anticancer activity. Advancement in the area of chemoprevention during the past years has been very inspiring.

Accumulating epidemiological evidences have exposed the chemopreventive efficacy of many medicinal plants and their phytochemicals in prevention of the disease. Many drugs have been discovered by screening phytochemicals from medicinal plants, animals, marine and microorganisms. Vinblastine, vincristine, paclitaxel, etoposide, teniposide, irinotecan and topotecan are few examples of plant derived drugs that are employed in chemotherapy. Many phytoconstituents are also known to possess chemopreventive property against several cancers. Moreover many naturally occurring plant based drugs gaining attention for the intervention of cancer invasion in late stage of this disease (Aggarwal and Shishodia, 2006; Ravindranath et al., 2009).

Indigofera linnaei Ali. (Tamil Name: Cheppu Nerinjil) belongs to the family Fabaceae and is a reputed medicinal plant in India. It is a small trailing, much branched annual or biennial herb, distributed throughout India. Literature review reveal that three nitropropanoyl esters of glucose namely 1,2,6-tri-O-(3nitropropanoyl)- $\beta$ - $\quad$ D-glucopyranose, $\quad 2,3,4,6$-tetra-O-(3nitropropanoyl)- $\alpha$ - $\quad$ D-glucopyranose and 3,4,6-tri-O-(3nitropropanoyl)- $\alpha$-D-glucopyranose were isolated from the aerial parts of Indigofera linnaei (Majak et al., 1992).

The plant exhibit wound healing activity in rats (Hemalatha et al., 2001). A new isoflavone namely 7,8methylenedioxy-4'-methoxyisoflavone has been isolated from the entire plant of Indigofera linnaei (Rajendraprasad and Chakradhar, 2004). In our earlier studies, the plant extract exhibited a potent free radical scavenging and antioxidant activity (Kumar et al., 2011a), anticancer activity (Kumar et al., 2011b), antiinflammatory and analgesic activities via inhibition of nitric oxide, lipoxygenase and cyclooxygenase (Kumar et al., 2016).

In continuation of our previous works on this plant, the present study is designed to study the chemopreventive property of methanolic extract of $I$. linnaei (MEIL) on DEN induced phenobarbital promoted liver tumour model in male Wistar rats.

\section{MATERIALS AND METHODS}

\section{Chemicals}

Diethylnitrosamine (DEN) and phenobarbital (PB) were purchased from Sigma Chemicals Co. (St. Louis, MO, USA). Silymarin was procured from Micro Labs, Hosur, India. All other chemicals used for experiments were of analytical grade.

\section{Plant material and extraction}

Entire plants of I. linnaei were collected from the foothills of Yercaud in the month of November 2014. The plant was authenticated by Dr. G.V.S. Murthy, Joint Director, Botanical Survey of India, Coimbatore, Tamilnadu, India. A voucher specimen is preserved in our laboratory for future reference (Voucher No.: P. Ch. IL 002).

The plant material was shade dried, pulverized and extracted $(500 \mathrm{~g})$ by cold maceration process with $80 \%$ methanol at room temperature for $72 \mathrm{~h}$. The extract was filtered and concentrated to dryness under reduced pressure and controlled temperature $\left(40{ }^{\circ} \mathrm{C}\right.$ to $\left.50{ }^{\circ} \mathrm{C}\right)$ in a rotary evaporator. The extract was a dark yellowish brown solid and was preserved in a vacuum desiccator until further use.

\section{Animals}

Male Wistar rats (150-160g) were purchased from Venkateshwara Enterprises, Bangalore, India. The animals were housed in microloan cages in controlled temperature $\left(25 \pm 2{ }^{\circ} \mathrm{C}\right)$ and light cycle (12h dark/light) and fed with standard laboratory pellet diet with water ad libitum. The study was conducted after obtaining Institutional Animal Ethical Committee (IAEC) clearance.

\section{Experimental design}

The rats were divided into five groups, each group consisting of six animals. Liver tumour was induced in group II-V with single intraperitoneal injection of DEN at a dose of 200 $\mathrm{mg} / \mathrm{kg}$ body weight, in saline. Two weeks after DEN administration, carcinogenic effect was promoted by $0.05 \%$ phenobarbital, which was supplemented to the animals through drinking water up to 16 successive weeks (Rajkapoor et al., 2005; Singh et al., 2009).

Group I animals were served as normal control which received $1 \mathrm{ml} / \mathrm{kg}$ body weight of $0.3 \%$ Carboxymethyl cellulose (CMC) through oral route. Group II animals served as DEN control group, received vehicle. Group III animals were treated with standard drug silymarin at a dose of $200 \mathrm{mg} / \mathrm{kg}$ by oral route, whereas group IV and V animals were treated with MEIL at a dose of 200 and $400 \mathrm{mg} / \mathrm{kg}$ by oral route, respectively (Kumar et al., 2011b; Kumar et al., 2016). All the treatments were given for 16 weeks after the administration of DEN on 5 days per week. At the end of experimental period, animals were fasted overnight and sacrificed by cervical decapitation. Blood was collected and serum was separated out. The liver was immediately removed, weighed and grossly examined for the tumour nodes and 
tumour incidence. A small portion of liver was fixed in $10 \%$ formalin for histopathological studies.

\section{Serum biochemical and tumour markers estimation}

Serum was analysed for serum aspartate transaminase (AST), serum alanine transaminase (ALT), alkaline phosphatase (ALP), total protein, total bilirubin, total cholesterol, gamma glutamate transpeptidase (GGTP), lactate dehydrogenase (LDH) and prothrombin time by using commercial kits (Agappe Diagnostics and Ecoline Diagnostic Kits, India) according to the manufacturer's instruction. Liver tumour markers such as Alpha fetoprotein (AFP) and Carcinoembryonic antigen (CEA) in rat serum was estimated by using commercially available ELISA kits (USCN Life Science Inc. Wuhan, China).

Vasculoendothelial growth factor (VEGF) and Tumour Necrosis Factor $-\alpha$ (TNF- $\alpha)$ in rat serum was estimated by using commercially available ELISA kit (RayBio, RayBiotech, Inc. USA) according to the manufacturer's instruction.

A $10 \%$ homogenate of liver tissue was used for analysis of lipid peroxidation (LPO) (Devasagayam and Tarachand, 1987), catalase (CAT) (Sinha, 1972), superoxide dismutase (SOD) (Marklund and Marklund, 1974), glutathione peroxidase (GPx) (Rotruk et al., 1973) and glutathione S-transferase (GST) (Habig et al., 1974). The liver homogenate was also used for the estimation of DNA, RNA (Schneider, 1957; Burton, 1956) and protein content (Lowry et al., 1951) in liver tissues.

\section{Histopathological examination}

The portion of the liver previously fixed in formalin was embedded in paraffin, sectioned at $5 \mu \mathrm{m}$ and stained with haemotoxylin-eosin. Light microscopy was used to evaluate pathological changes of liver.

\section{Statistical analysis}

The values were expressed as mean \pm SEM. Statistical analysis were performed by one way analysis of variance (ANOVA) followed by Tukey's multiple comparison test using GraphPad Prism software (Version 5.0) for the determination of level of significance. $\mathrm{P}$ value $<0.05$ was considered as significant.

\section{RESULTS}

\section{Effect of MEIL on body weight}

Methanol extract of I. linnaei at a dose of $200 \mathrm{mg}$ and $400 \mathrm{mg}$ once daily for 16 weeks and standard silymarin at a dose of $200 \mathrm{mg} / \mathrm{kg}$ were used for studying the body weight changes in HCC rats.

The results revealed that the body weights were significantly decreased $(\mathrm{P}<0.001)$ in $\mathrm{DEN}$ treated group. However, extract treatment showed significant protection in body weight $(\mathrm{P}<0.001)$ when compared to DEN control group. Standard drug silymarin also significantly increased the body weight than the DEN treated animals but no significant difference was observed between the extract treated animals and silymarin treated animals. This indicates that the extract is equally potent to silymarin. The body weight changes are presented in Fig. 1.

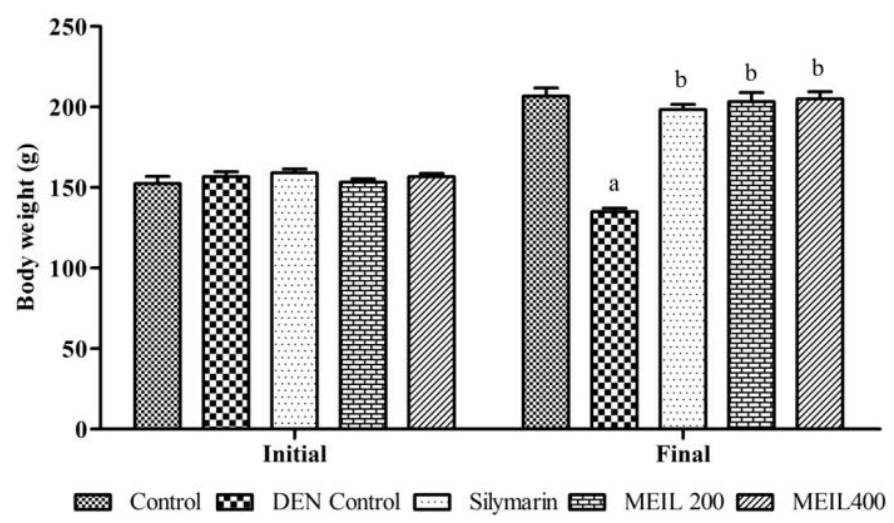

Fig. 1: Effect of MEIL on body weight of liver tumour bearing animals. $\mathrm{N}=6$; Data are expressed as Mean \pm SEM; ${ }^{a} \mathrm{P}<0.001$ vs control; ${ }^{\mathrm{b}} \mathrm{P}<0.001$ vs DEN control. Data were analysed by using Tukey-Kramer multiple comparison test.

\section{Effect of MEIL on liver weight, relative liver weight and tumour incidence}

The study showed that the liver weights were significantly increased in DEN control group. However, treatment with extract of I. linnaei, showed significant protection in liver weight. Whereas, standard drug silymarin show significant reduction in relative liver weight compared to DEN control group. No significant difference was observed between silymarin and extract treated groups in relative liver weight. Extract treatment at the tested dose levels significantly reduced the number of tumour nodes and tumour incidence on DEN treated animals. Effect of methanol extract of I. linnaei on liver weight, relative liver weight and tumour incidence are presented in Fig. 2.

\section{Effect of MEIL on serum hepatic parameters}

From the table 1, it is clearly evident that DEN treatment caused significant elevation of liver serum markers. In the DEN treated group, the level of AST, ALT, ALP, GGTP, LDH, total cholesterol, total bilirubin and total protein were significantly elevated $(\mathrm{P}<0.001$ to $\mathrm{P}<0.05)$. A significant increase in prothrombin time was also observed in DEN treated animals. In contrast, the groups treated with MEIL prevented the carcinogenesis process and the chemopreventive effect of the extract was confirmed by the significant alterations in the serum hepatic parameters.

The extract treatment was able to reverse all the elevated serum hepatic parameters to near normal and the results were comparable to that of standard silymarin treated group. 
A)

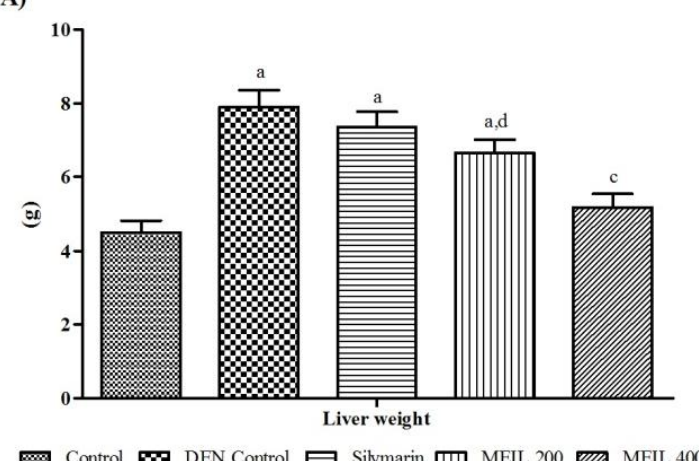

C)

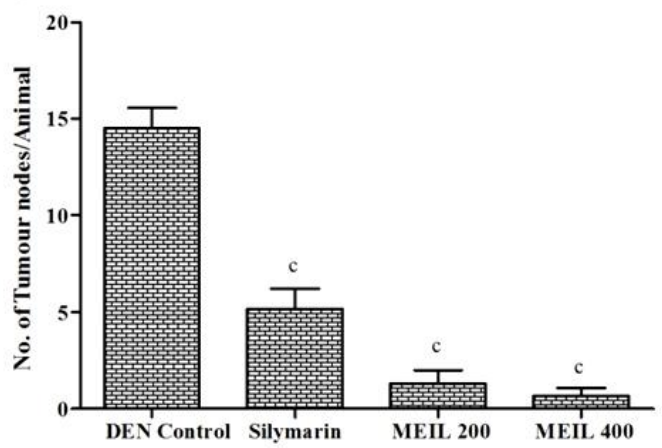

B)

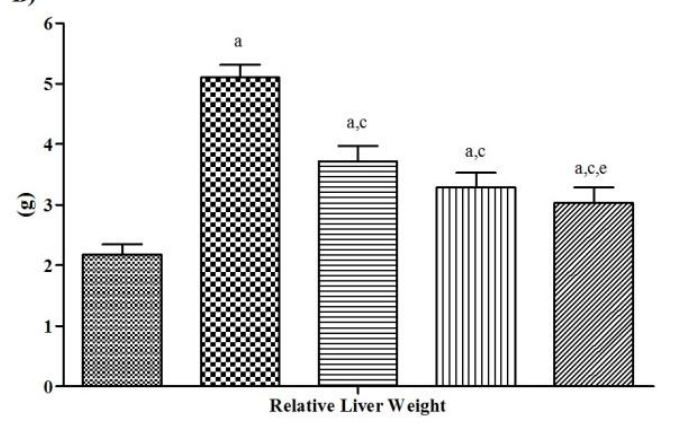

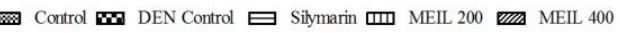

D)

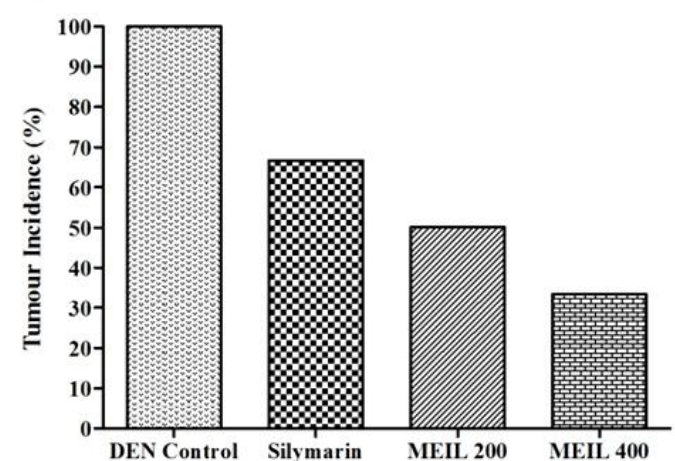

Fig. 2: Effect of MEIL on liver weight, relative liver weight, tumour nodes and tumour incidence of liver tumour bearing animals. N=6; Data are expressed as Mean \pm SEM; ${ }^{\text {a }} \mathrm{P}<0.001 ;{ }^{b} \mathrm{P}<0.01$ vs control; ${ }^{\mathrm{c}} \mathrm{P}<0.001 ;{ }^{\mathrm{d}} \mathrm{P}<0.01$ vs DEN control; ${ }^{\mathrm{e}} \mathrm{P}<0.05$ vs silymarin. Data were analysed by using Tukey-Kramer multiple comparison test.

Table 1: Effect of MEIL on serum hepatic parameters of DEN induced hepatocellular carcinoma.

\begin{tabular}{|c|c|c|c|c|c|c|c|c|c|}
\hline $\begin{array}{l}\text { Design of } \\
\text { treatment }\end{array}$ & $\begin{array}{c}\text { AST } \\
(\mathbf{I U} / \mathbf{L})\end{array}$ & $\begin{array}{c}\text { ALT } \\
(\mathbf{I U} / \mathbf{L})\end{array}$ & ALP (IU/L) & $\begin{array}{c}\text { Total } \\
\text { Proteins } \\
\text { (g/dL) }\end{array}$ & $\begin{array}{c}\text { Total } \\
\text { Bilirubin } \\
\text { (mg/dL) }\end{array}$ & $\begin{array}{c}\text { Total } \\
\text { Cholesterol } \\
(\mathrm{mg} / \mathrm{dL})\end{array}$ & $\begin{array}{l}\text { GGTP } \\
\text { (IU/L) }\end{array}$ & LDH (IU/L) & $\begin{array}{c}\text { Prothrombin } \\
\text { time (Sec.) }\end{array}$ \\
\hline$\overline{\text { Con }}$ & 110.7 & $68.37 \pm 2.71$ & 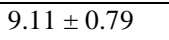 & $5.96 \pm 0.24$ & $0.52 \pm 0.05$ & $95.33 \pm 5.58$ & 10.4 & $72 \pm 2.08$ & 15. \\
\hline DEN control & $230.7 \pm 13.5^{\mathrm{a}}$ & $188.3 \pm 3.4^{\mathrm{a}}$ & $15.37 \pm 2.07^{\mathrm{a}}$ & $9.27 \pm 0.25^{\mathrm{a}}$ & $2.96 \pm 0.24^{\mathrm{a}}$ & $157.3 \pm 7.98^{\mathrm{a}}$ & $28.67 \pm 1.69^{\mathrm{a}}$ & $151.32 \pm 10.22^{\mathrm{a}}$ & $48.3 \pm 2.75^{\mathrm{a}}$ \\
\hline Silymarin & $170.83 \pm 7.91^{\mathrm{b}, \mathrm{e}}$ & $67 \pm 2.9^{\mathrm{d}}$ & $8.33 \pm 0.74^{\mathrm{d}}$ & $6.27 \pm 0.23^{\mathrm{d}}$ & $0.88 \pm 0.05^{\mathrm{d}}$ & $101 \pm 3.75^{\mathrm{d}}$ & $12.53 \pm 1.27^{\mathrm{d}}$ & $86.08 \pm 3.2^{\mathrm{d}}$ & $35 \pm 0.73^{\mathrm{a}, \mathrm{d}}$ \\
\hline MEIL 200 & $142.17 \pm 9.27^{\mathrm{d}}$ & $91.83 \pm 3.89^{\mathrm{b}, \mathrm{d}, \mathrm{g}}$ & $9.82 \pm 0.54^{\mathrm{e}}$ & $5.86 \pm 0.18^{\mathrm{d}}$ & $0.69 \pm 0.08^{\mathrm{d}}$ & $102 \pm 1.86^{\mathrm{d}}$ & $13 \pm 0.61^{\mathrm{d}}$ & $66.05 \pm 3.66^{\mathrm{d}}$ & $24.5 \pm 1.99^{\mathrm{c}, \mathrm{d}, \mathrm{g}}$ \\
\hline MEIL 400 & $126.5 \pm 1.78^{\mathrm{d}}$ & $75.73 \pm 2.68^{\mathrm{d}}$ & $8.33 \pm 0.43^{\mathrm{d}}$ & $5.95 \pm 0.33^{\mathrm{d}}$ & $0.51 \pm 0.03^{\mathrm{d}}$ & $101 \pm 4.03^{\mathrm{d}}$ & $12.32 \pm 1.36^{\mathrm{d}}$ & $74.42 \pm 5.07^{\mathrm{d}}$ & $19.83 \pm 1.93^{\mathrm{d}, \mathrm{f}}$ \\
\hline
\end{tabular}

$\mathrm{N}=6$; Data are expressed as Mean $\pm \mathrm{SEM} ;{ }^{\mathrm{a}} \mathrm{P}<0.001 ;{ }^{\mathrm{b}} \mathrm{P}<0.01 ;{ }^{\mathrm{c}} \mathrm{P}<0.05$ vs control. ${ }^{\mathrm{d}} \mathrm{P}<0.001 ;{ }^{\mathrm{e}} \mathrm{P}<0.01$ vs DEN control. ${ }^{\mathrm{f}} \mathrm{P}<0.001 ;{ }^{\mathrm{g}} \mathrm{P}<0.01$ vs silymarin. Data were analysed by using Tukey-Kramer multiple comparison test.

\section{Effect of MEIL on antioxidant enzyme levels}

Fig. 3 illustrated the lipid peroxidation and the enzymic antioxidant level in liver of experimental animals. Administration of DEN led to increase in the levels of lipid peroxidation and decrease in catalase, superoxide dismutase, glutathione peroxidase and glutathione S-transferase levels in the liver homogenate $(\mathrm{P}<0.001$ to 0.01$)$. Treatment of rats with MEIL at the tested dose levels prevented the DEN induced alterations of above said parameters. The protection produced by the extract was comparable with that of the standard silymarin.

\section{Effect of MEIL on liver tumour markers, VEGF and TNF - $\alpha$}

Alpha fetoprotein (AFP) and carcinoembryonic antigen (CEA) are the specific liver tumour markers, which were found to be significantly increased in DEN treated animals $(\mathrm{P}<0.001)$. Vasculoendothelial growth factor (VEGF) and tumour necrosis factor alpha (TNF- $\alpha$ ) levels were also found to be increased significantly when compared to control group. Treatment with methanol extract of I. linnaei at the tested dose levels significantly reduces the elevated levels of tumour specific markers and cytokine levels in dose dependent manner. The results obtained were comparable with standard silymarin. The tested plant extract at higher dose level significantly reduce elevated levels of these biomarkers than silymarin. The values are presented in Fig. 4.

\section{Effect of MEIL on nucleic acids and protein content}

It is clearly evident from the table 2 that DEN caused significant elevation of DNA and RNA and decrease in protein content in liver tissue. In contrast, the groups treated with MEIL decreased the elevated levels of DNA and RNA and increase the protein level towards normalization. The results produced by the extract were almost comparable with standard drug silymarin. The histological observations also basically support the results obtained (Fig. 5 A-E). 
A)

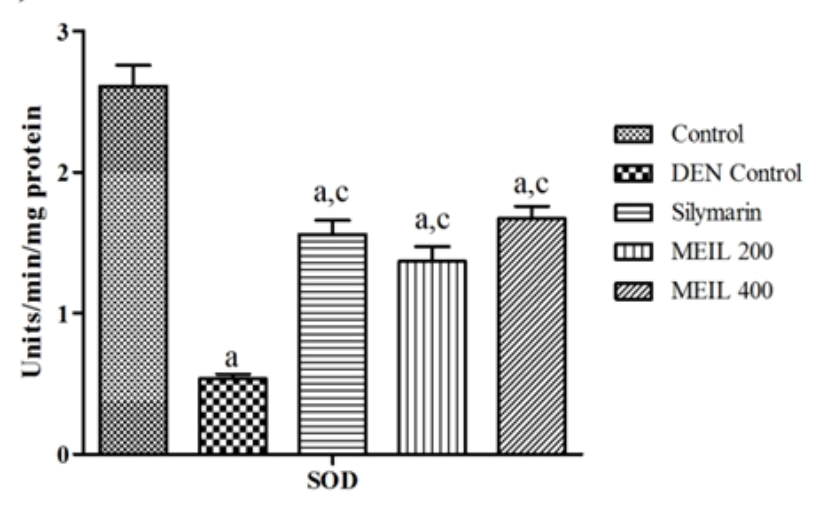

C)

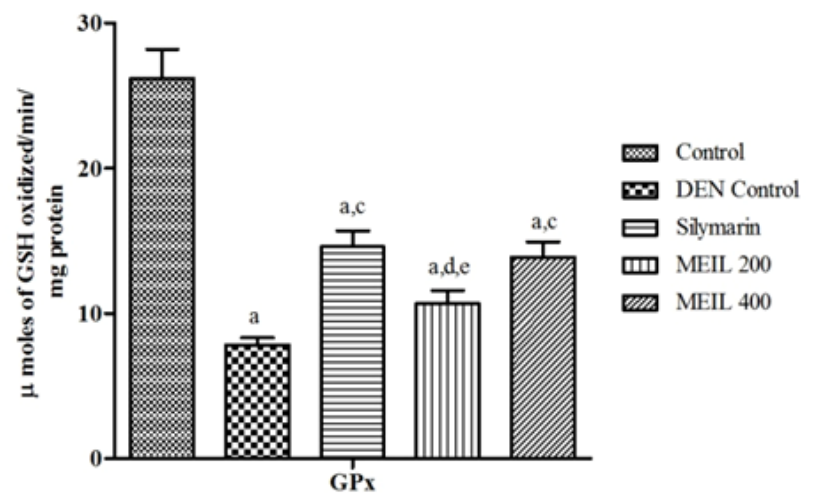

B)

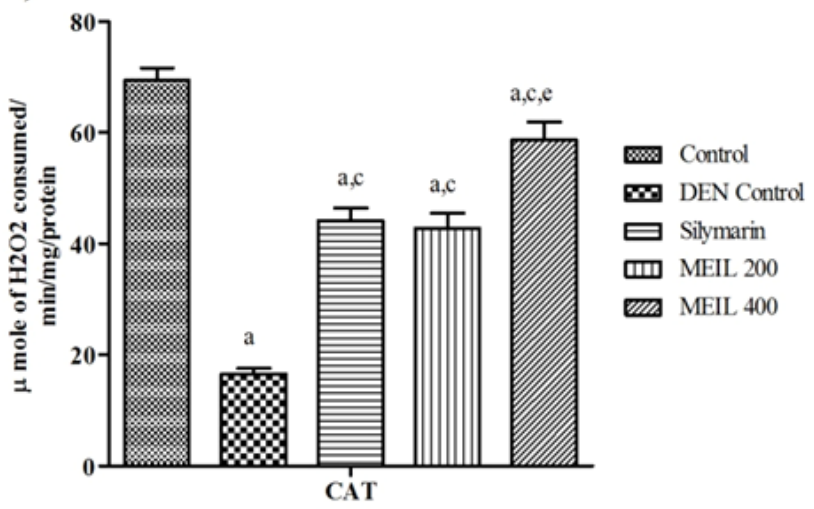

D)

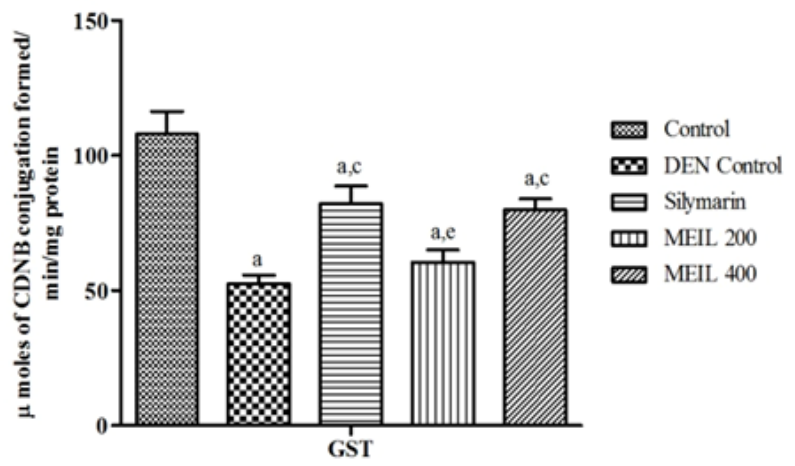

E)

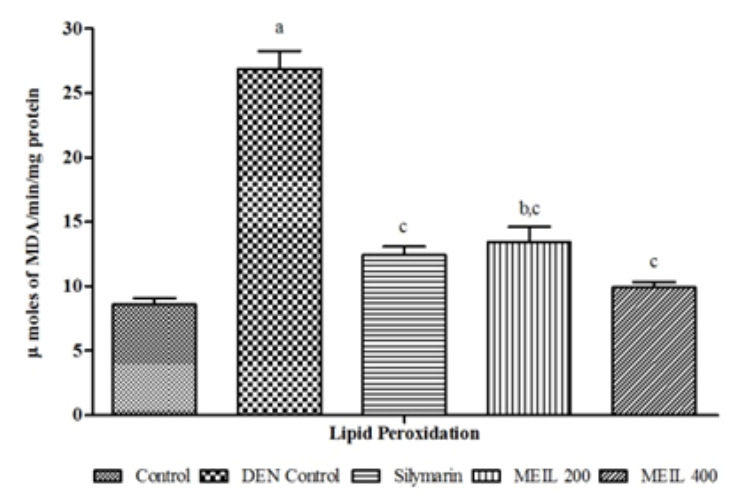

Fig. 3: Effect of MEIL on antioxidant enzyme levels and lipid peroxidation of DEN induced liver tumour bearing animals. N=6; Data are expressed as Mean \pm SEM; ${ }^{\mathrm{a}} \mathrm{P}<0.001 ;{ }^{\mathrm{b}} \mathrm{P}<0.01$ vs control. ${ }^{\mathrm{c}} \mathrm{P}<0.001 ;{ }^{\mathrm{d}} \mathrm{P}<0.05$ vs DEN control. ${ }^{\mathrm{e}} \mathrm{P}<0.001$ vs silymarin. Data were analysed by using Tukey-Kramer multiple comparison test. A) SOD, units $/ \mathrm{min} / \mathrm{mg}$ protein; B) CAT, $\mu$ mole of $\mathrm{H}_{2} \mathrm{O}_{2}$ consumed $/ \mathrm{min} / \mathrm{mg}$ protein; C) GPx, $\mu$ moles of GSH oxidized $/ \mathrm{min} / \mathrm{mg}$ protein; D) GST, $\mu$ moles of CDNB conjugation formed $/ \mathrm{min} / \mathrm{mg}$ protein; E) LPO, $\mu$ moles of MDA $/ \mathrm{min} / \mathrm{mg}$ protein.

Table 2: Effect of MEIL on DNA, RNA and protein content of DEN induced hepatocellular carcinoma

\begin{tabular}{|c|c|c|c|}
\hline $\begin{array}{c}\text { Design of } \\
\text { Treatment }\end{array}$ & $\begin{array}{l}\text { DNA (mg/g } \\
\text { of wet tissue) }\end{array}$ & $\begin{array}{l}\text { RNA (mg/g } \\
\text { of wet tissue) }\end{array}$ & $\begin{array}{c}\text { Proteins (mg/g } \\
\text { of wet tissue) }\end{array}$ \\
\hline Control & $6.31 \pm 0.28$ & $8.02 \pm 0.41$ & $8.76 \pm 0.32$ \\
\hline DEN control & $9.10 \pm 0.39^{\mathrm{a}}$ & $10.49 \pm 0.72^{\mathrm{b}}$ & $5.09 \pm 0.3^{\mathrm{a}}$ \\
\hline Silymarin & $5.95 \pm 0.2^{\mathrm{d}}$ & $7.2 \pm 0.39^{d}$ & $7.24 \pm 0.35^{\mathrm{c}, \mathrm{d}}$ \\
\hline MEIL 200 & $7.4 \pm 0.23^{\mathrm{d}}$ & $9.22 \pm 0.23$ & $6.39 \pm 0.3^{\mathrm{a}}$ \\
\hline MEIL 400 & $6.37 \pm 0.23^{\mathrm{d}}$ & $7.14 \pm 0.53^{\mathrm{d}}$ & $7.97 \pm 0.28^{\mathrm{d}}$ \\
\hline
\end{tabular}

$\mathrm{N}=6$; Data are expressed as Mean $\pm \mathrm{SEM} ;{ }^{\mathrm{a}} \mathrm{P}<0.001,{ }^{\mathrm{b}} \mathrm{P}<0.01,{ }^{\mathrm{c}} \mathrm{P}<0.05$ vs control; ${ }^{\mathrm{d}} \mathrm{P}<0.001$ vs DEN control. Data were analysed by using Tukey-Kramer multiple comparison test. 
A)

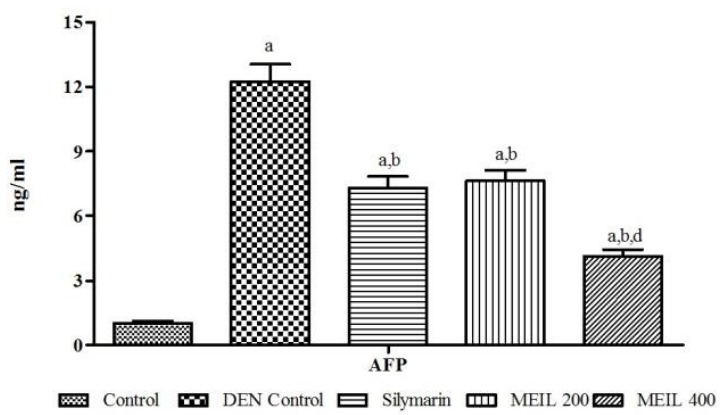

B)

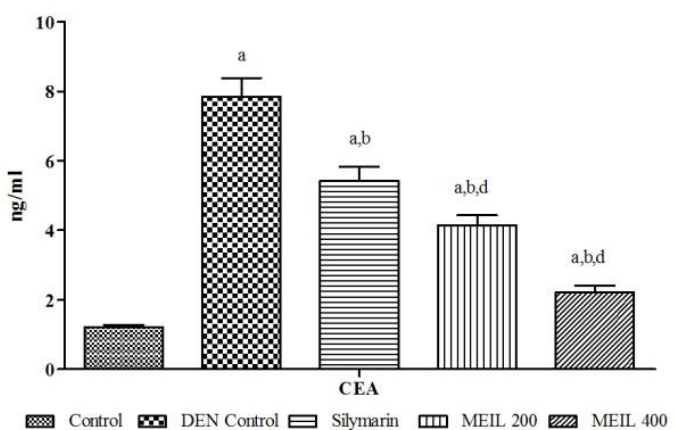

D)

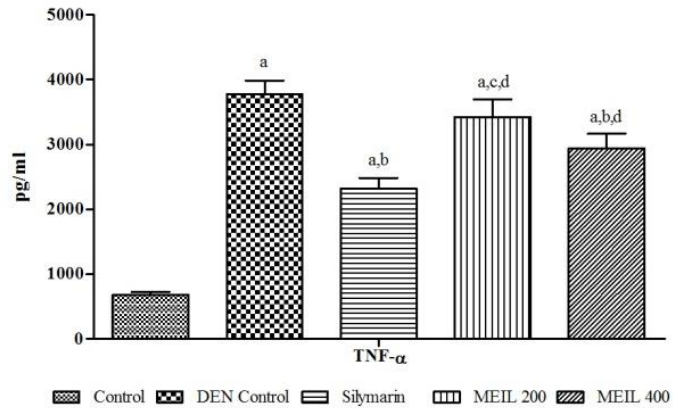

Fig. 4: Effect of MEIL on liver tumour markers of DEN induced liver tumour bearing animals. N=6; Data are expressed as Mean $\pm \mathrm{SEM}$; ${ }^{\mathrm{a}} \mathrm{P}<0.001 \mathrm{vs}$ control. ${ }^{\mathrm{b}}$ $\mathrm{P}<0.001 ;{ }^{\mathrm{c}} \mathrm{P}<0.01$ vs DEN control. ${ }^{\mathrm{d}} \mathrm{P}<0.001$ vs silymarin. Data were analyzed by using Tukey-Kramer multiple comparison test. A) Alpha fetoprotein B) Carcinoembryonic antigen C) Vasculoendothelial growth factor D) Tumour Nectrosis Factor $-\alpha$.

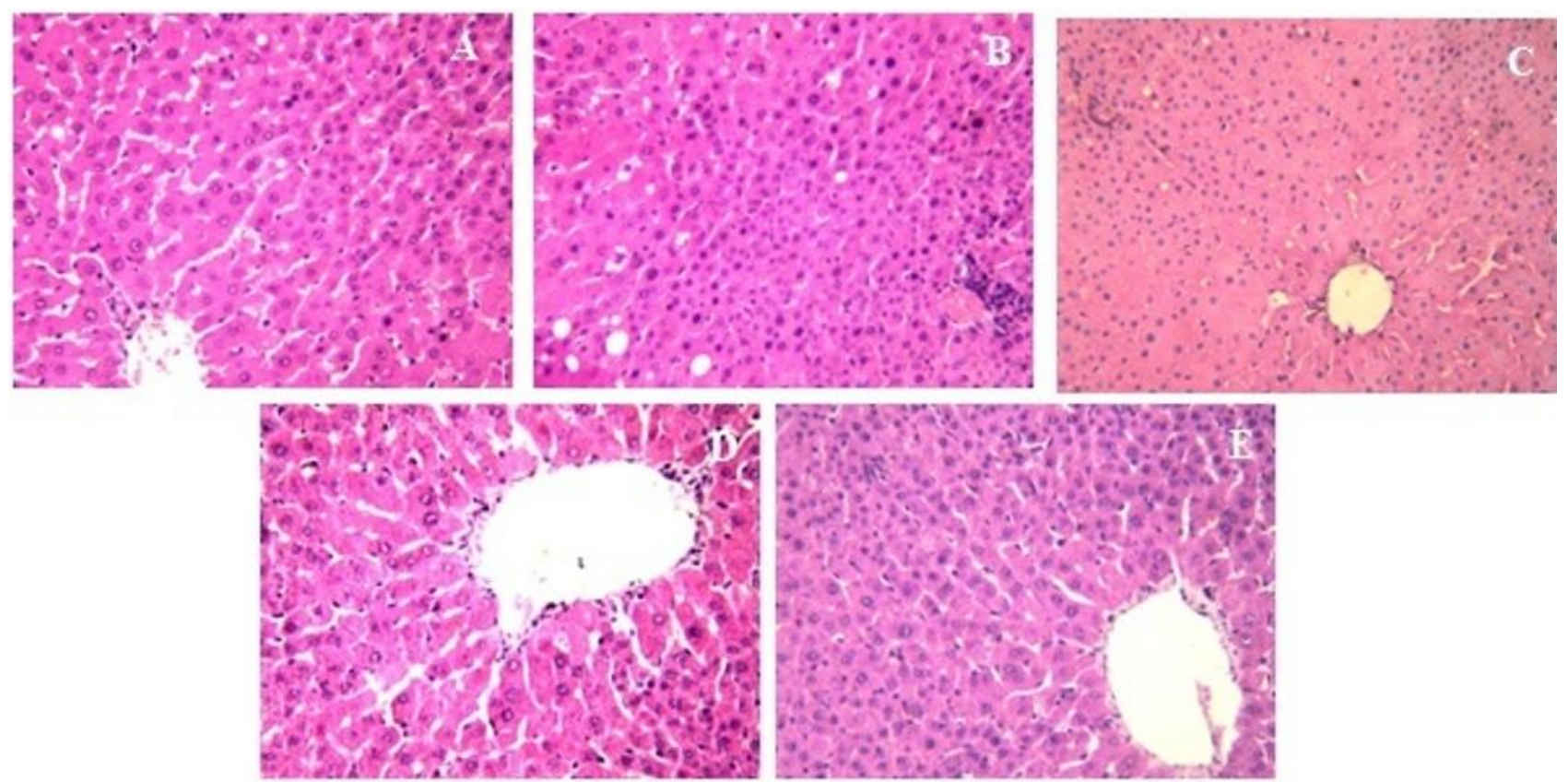

Fig. 5: A-E represents the histological examination of liver viewed under light microscope in control and experimental animals (Hematoxyllin and Eosin staining $x$ 400). Fig. 5A: Liver from normal control group revealing normal architectural pattern with central vein and hepatic cords. Fig. 5B: Liver from tumour control group revealing monotonous sheet arrangement of neoplastic, multi-nucleated, highly proliferating hepatocytes. Fig. 5C: Liver from Silymarin treated group showing lack of inter-hepatic cord space and pleomorphic hepatocytes. Fig. 5D: Liver Hepatocytes of MEIL 200mg treated group showing mild pleomorphism.

Fig. 5E: Liver from MEIL $400 \mathrm{mg}$ treated group revealing almost normal architecture and normal radiating hepatic cords. 


\section{DISCUSSION}

Hepatocellular carcinoma (HCC) is a major problem not only in developed countries but also in most developing countries. It is one of the dreadful cancers with a worldwide incidence of over one million cases every year (Jemal et al., 2011). It is induced by toxic industrial chemicals, air pollutants, water contaminants, food additives and fungal toxins (Park et al., 2009). DEN predominantly induces liver tumours in various species, but other nitrosamines may have varied effects. It is widely accepted that metabolic activation of nitrosamines by cytochrome $\mathrm{P}_{450}$ enzyme to reactive electrophiles is required for their cytotoxic mutagenic and carcinogenic activity. Because of its relatively simple metabolic pathway and potent carcinogenic activity, DEN has found widespread use as an experimental model in the field of carcinogenesis and in chemoprevention (Borbath et al., 2010). A large number of agents including natural and synthetic compounds have been identified as having some potential cancer chemopreventive value. Plants and plant products have been shown to play an important role in the management of various liver disorders. The present study was undertaken to establish the cancer chemopreventive effect of MEIL against DEN induced liver tumour.

In the present study, the effect of methanolic extract of Indigofera linnaei in body weight changes in HCC were carried and showed a significant result in treatment. Liver cancer may engender complex metabolic disturbances in both human and experimental animals resulting in rapid loss of body weight and tissue wasting. There is an appreciable loss in body weight in HCC bearing rat as compared to control rats and the reduction in body weight (Glory and Thiruvengadam, 2012). The body weights steadily increased after treatment with extract and were compared with standard silymarin which indicate that the extract reduces the tumour incidence and changes in energy metabolism and also shows anticarcinogenic potency.

Relative liver weight is an important parameter in judging the pathological conditions of liver. Relative liver weight was significantly increased in DEN treated animals, which is due to the increase in liver weight without increase in body weight of the tumour bearing animals. The increase in relative liver weight could be due to hyperplasia, hypertrophy and induction of cirrhosis of liver by DEN (Roy and Gadad, 2016). The administration of MEIL and silymarin decreased the liver weight and relative liver weight which shows the rehabilitating capability of extract in respect with chemopreventive potency in comparison with the standard drug silymarin. Our results are in good agreement with the previous report (Ghosh et al., 2012). Many experimental studies reveals tumour nodules are the precursors of hepatic cancer and also severity of hepatocarcinogenesis may correlates with number and incidence of tumour nodules (Sell and Leffert, 2008). Several nodes were found in DEN treated animals. Treatment with MEIL significantly decreases the nodule growth and reduction of tumour incidence which establish chemopreventive property of MEIL. The extract treatment also delays the tumour onset which was confirmed by reduced morphological changes establishes the evidence for cancer preventive effect against HCC.

Biochemical liver marker enzymes are used to screen particularly tumour conditions for differential diagnosis, prognosis, monitoring the progress and for assessing the response to therapy. These enzymes are more unique and changes in their activities reflect the effect of proliferation of cells with growth potential and its metabolic turnover. The rise in their activities is shown to be in good correlation with the number of transformed cells in cancer conditions. These enzymes serve as an index of liver cell injury and can be used to identify or confirms liver diseases. The relatively similar elevations of the liver specific enzymes are considered as the most sensitive markers in the diagnosis of hepatocellular damage and loss of functional integrity of the cell membrane. The carcinogenesis process in the liver also affecting the liver cells with subsequent breakdown in membrane architecture of the cells leads to their release in to sera where their levels goes high (Ramakrishnan et al., 2007). In the present investigation, animals treated with DEN causes hepatocellular damage which was observed from significant increase in the serum liver marker enzymes like AST, ALT, ALP, LDH and GGTP. These kind of elevations were also observed by several research groups (Glory and Thiruvengadam, 2012; Dhanasekaran et al., 2009; Roy and Gadad, 2016). The raised levels of these markers are significantly reduced to near normal in HCC bearing animals that shows the anticarcinogenic activity of the extract. This result shows the antineoplastic effect of plant extract as with the standard drug silymarin.

The elevated levels of lipids in tumour bearing animals may be due to decreased activities of lipid metabolizing enzymes. This predicts the defective catabolism rather than an elevated synthesis of lipoprotein which seems to be the cause. The total bilirubin level is a biomarker for liver damage. The accumulation of bilirubin in the serum is a result of decreased biliary excretion after the conjugation of bilirubin in the liver rather than the result of an increased bilirubin load caused by haemolysis. In hepatic tumours haemolysis plus deranged liver function leads to hyperbilirubinemia. In the present investigation, the $\mathrm{HCC}$ bearing animals showed an elevation in levels of serum bilirubin which may be due to the leakage of plasma membrane and loss of functional integrity of cell membranes in liver (Sivaramakrishnan et al., 2008; Chen et al., 2012).

The groups treated with MEIL showed significant results, reducing the elevated levels in a dose dependent manner which indicates the restoration of bilirubin level as well as total cholesterol level. Proteins and its synthesis is an important phenomenon in normal as well as in neoplastic conditions. The highest rate of synthesis of tissue proteins and major protein mass is severely affected by cancer. In the present investigation also a decline in protein content was observed in DEN treated animals and this may be due to the use of host protein for cancer development. MEIL administration increased the protein content which indicates that the plant extract is involved in the maintenance of macromolecules such as proteins. 
When liver function is severely abnormal, the synthesis and secretion of clotting proteins into the blood is decreased. The prothrombin time is prolonged when the blood concentrations of some of the clotting factors made by the liver are low. In noncholestatic chronic liver diseases, the prothrombin time is not elevated usually until cirrhosis and significant liver damage occur. In acute liver diseases, the prothrombin time can be prolonged and return to normal as the patients recover (Toyoda et al., 2015). In the present study, prothrombin time was increased in tumour control animals whereas it was brought back to normal in treatment groups. This indicates the chemopreventive effect of plant extract.

DEN treatment increase the levels of lipid peroxidation in carcinogenic process may be due to abnormal levels of reactive oxygen species (ROS) that react with membrane lipids (Singh et al., 2004). Measurement of tissue malondialdehyde (MDA), one of the end products of lipid peroxidation, is commonly used as an indirect index for assessing the extent of lipid peroxidation in tissues (Pracheta et al., 2011). The treatment with MEIL lowered the malanoaldehyde (MDA) levels in comparison with HCC bearing animals. Therefore it is convenient to suggest that the extract definitely have beneficial effect on diethylnitrosamine induced HCC. The presence of flavonoids may contribute this effect because they are proved to be potent inhibitors of conjugated dienes and are able to inhibit lipid peroxidation. Phenobarbital is a tumour promoter and it has a strong inhibitory effect on cellular antioxidant defense system like SOD, CAT, GST and GPx (Yadav and Bhatnagar, 2007). SOD accelerates transformation of superoxide anions to hydrogen peroxide, while catalase or GPx converts hydrogen peroxide to water. A sharp fall in these antioxidant enzymes can be due to increased free radicals production during the metabolism of DEN and phenobarbital. Upon treatment with MEIL, a dose dependent increase in the levels of antioxidant enzymes and the results were almost equal to the standard drug silymarin. In addition, our research group found that I. linnaei acts as a potent free radical scavenging, antioxidant enzyme inducing and having antitumour properties (Kumar et al., 2011a; Kumar et al., 2011b). The plant extract also contains rich in flavonoids, phenolics, ascorbic acid and tannins which might modulate the oxidative status via free radical scavenging and antioxidant enhancing activities in rat liver.

The most commonly used tumour markers for the diagnosis of hepatocellular carcinoma (HCC) is Alpha fetoprotein (AFP) which is a unique immunomodulatory glycoprotein, which is normally made by the immature hepatocytes in the fetus. AFP is initially thought to be specific for primary liver cancer but it has been found in the serum of normal individuals. However, approximately in $70 \%$ of the patients with primary liver cancer, the serum AFP level may be markedly elevated. Detection of AFP during monitoring of liver cancer treatment is well accepted in patients with increased AFP levels before therapy. It has been recognized that exposure of animals with DEN increases the circulating AFP levels. In our study, the results showing significant rise in levels of AFP in tumour bearing animals and that were found to be reduced in extract treated animals and our results are more consistent with the previous studies (Singh et al., 2009; Sivaramakrishnan et al., 2008; Taha et al., 2010; El Miniawy et al., 2014).

Carcinoembryonic antigen (CEA) is an oncofetal glycoprotein, which is expressed in normal mucosal cells and is over expressed in liver and colon cancers. It is frequently detected in high concentrations in the serum of individuals with liver tumours. It is clear that the CEA assay is a better indicator of liver cancer. In the present study, a significant increase in serum CEA levels following DEN treatment was associated with production rate of tumours, their location, stage, size, vascularity and differentiation. Reduction in CEA expression in extract treated groups indicates the decreased proliferation rate of liver tumours. Our findings are in good agreement with earlier reports (Jagan $e t$ al., 2008; Ramakrishnan et al., 2007). Tumour angiogenesis is the development of new vasculature from previous existing blood vessels. It is a major requirement for tumour growth and metastasis which is regulated by pro and antiangiogenic factors. Physiologically, under normal circumstances angiogenesis does not occur. Under certain circumstances, such as tumour formation or wound healing, the positive regulation of angiogenesis predominates and the endothelium becomes activated. Vascular endothelial growth factor (VEGF) and angiogenin are important angiogenic factors of neoangiogenesis. VEGF is a primary stimulant of angiogenesis. It is a multifunctional cytokine, induced by hypoxia and oncogenic mutation (Zaghloul et al., 2006) Excessive production of VEGF and angiogenin in HCC may contribute to angiogenesis, suggesting the potential role for the use of their antagonists in treating HCC. Antiangiogenesis has recently become the focus of the study for chemotherapy and chemoprevention. This is because antiangiogenic drugs inhibit the new blood vessels growth that provides the tumour with nutrients and oxygen which are essential for the growth of tumour cells. Antiangiogenic agents are the inhibitors of growth factors and their receptors are promising therapeutic targets (Wills et al., 2006). Keeping this in mind, in the present study, the serum VEGF levels were estimated in liver tumour bearing animals. A significant rise in serum VEGF was observed in liver tumour bearing animals. Treatment with MEIL significantly reduces the VEGF levels to near normal. Many flavonoids such as genistein, kaempferol, apigenin, quercetin, luteolin, rutin and naringin have shown strong inhibition to cell proliferation and VEGF expression (Luo et al., 2008; Oak et al., 2005). Antiangiogenic activity of the plant extract may be due to the presence of rich amount of flavonoids present in the extract. Tumour Necrosis Factor - Alpha (TNF- $\alpha$ ) is a cytokine mainly produced by macrophages. It is highly expressed in tumours and thought to be pro-angiogenic. Interestingly, it is also a potent anti-vascular cytokine at higher doses and can be used clinically to destroy tumour vasculature. Unfortunately, TNF- $\alpha$ has powerful and toxic systemic side effects. Overexpression of TNF- $\alpha$ lead to upregulation of VEGF and induce angiogenesis and tumour metastasis. The role of TNF$\alpha$ may be responsible for initiation and progression of HCC. 
Elevated circulating TNF- $\alpha$ has been observed in patients with HCC. Hepatic expression of TNF- $\alpha$ is upregulated in autoimmune liver diseases, alcoholic hepatitis and HCC (Burton and Libutti, 2009; Yang, 2011) In the present study, a significant rise in the level of TNF- $\alpha$ was observed in tumour bearing animals. MEIL treatment significantly reduces the elevated TNF- $\alpha$ level. This indicates the complementary effect to the antiangiogenic activity of the plant extract. Nucleic acids play an important role during neoplastic transformation. The determination of nucleic acid content was more important with regards to biological and functional aspects of the tumour. Nucleic acid content is an index of proliferative activity in tumour conditions. Additionally their content is found to be an independent factor of prognosis, since the size of the tumour often correlates with the nucleic acid content of tumour. Deoxyribonucleic acid (DNA) and ribonucleic acid (RNA) synthesis was studied in order to determine the effects of silymarin along with MEIL on macromolecular synthesis in HCC. It has been observed that the tumour growth corresponds to the elevated levels of DNA and RNA synthesis. The level of DNA and RNA of liver found to be progressively increased in hepatocellular carcinoma bearing animals. Among the nucleic acids, RNA exhibited prominent increase than DNA. The increased nucleic acid synthesis in tumour animals was found to decrease when the animals were treated with MEIL and also shown the result effective when compared with the standard drug silymarin.

In the present investigation it has also been observed that decreased protein contents in plasma of HCC bearing animals appears which could be attributed to the impaired hepatic function resulting from infiltration with tumour. The liver is an important site of protein synthesis and it has the highest rate of synthesis of tissue proteins. Recycling of amino acids has been decreased in tumour conditions resulting in enhanced efflux of these amino acids from the tissues. Thus, the host responds to increased tumour load by increasing tissue protein breakdown. In HCC condition they exhibit hypoproteinemia. The administration of MEIL to the HCC bearing group resumed the protein level to near normal and also in comparison with the standard drug silymarin. DEN treatment induced histological changes in liver such as fatty infiltration, focal necrosis and hepatocytes having hyperchromatic nuclei. These changes are indicative of hepatocellular carcinoma. Further, histopathological studies showed normal architecture, mild congested sinusoids and absence of hepatocarcinoma cells in the livers of animals treated with the extract and DEN compared to those treated with DEN alone. All these results indicate that MEIL have chemopreventive effect against DEN induced liver tumour.

Our previous studies on this plant has been revealed that the plant extract was rich on many phytochemical compounds such as sterols, tannins, phenolics, flavonoids, alkaloids, terpenoids and saponins. Many such compounds are known to possess potent antitumor properties (Kintzios, 2006). The plan extract also exerts good radical scavenging and antioxidant activities in various in vitro models (Kumar et al., 2011a). The extract also has potent antitumour activity in animal models and it enhances the antioxidant enzyme system in tumour bearing animals (Kumar $e t$ al., 2011b). The plant extract is also having potent antiinflammatory and analgesic activity and this activity is mediated through the inhibition of inflammatory mediators such as nitric oxide, lipoxygenase and cyclooxygenase, which are known to play an important role in carcinogenesis process (Kumar et al., 2016).

Flavonoids are known to possess antimutagenic and anticancer effect. In addition to anticancer activity, flavonoids exert growth inhibitory effects on several malignant tumour cell lines in vitro. Moreover, flavonoids have a chemopreventive role in cancer through signal transduction in cell proliferation and angiogenesis (Weber et al., 1996; Fotsis et al., 1997). Flavonoids may inhibit carcinogenesis by inhibiting the metabolic activation of the carcinogen to its reactive intermediate, inducing the enzymes involved in the detoxification of the carcinogen and binding to reactive forms of carcinogens, thereby preventing their interaction with critical cellular targets such as DNA, RNA and proteins. In addition, plant flavonoids could also inhibit tumour promotional events as mentioned above. It is likely that flavonoids may emerge as a distinct group of antitumour agents. Previous studies have shown that the structural feature essential for antitumour activity of flavonoids in the presence of hydroxyl group in $5^{\text {th }}$ position of ' $A$ ' ring and 4' position of the ' $\mathrm{B}$ ' ring (Middleton et al., 2000). Most of the flavonoids have this structural feature and because of this structural feature, the flavonoids exhibit the anticarcinogenic activity. Saponins have been found beneficial targeted on inhibition of tumor angiogenesis by suppressing its inducer in the epithelial cells of blood vessels and then on adhering, invasion and metastasis of tumor cells. They also exhibit the antitumor effect by cell cycle arrest and apoptosis (Man et al., 2010). Plants from the Indigofera genus contains Indirubin, is a purple $3.2^{\prime}$-bis indole. It binds to and subsequently inhibits cyclin-dependent kinases (CDKs), glycogen synthase kinase 3 (GSK3) and the aryl hydrocarbon receptor and thus suppress the growth of various cell types through cell cycle arrest (Knockaert et al., 2004; Sugihara et al., 2004). Antitumour and chemopreventive effects of the extract may be due to the presence of these phytochemical constituents. Hence, the chemopreventive potential of methaolic leaf extract of I. linnaei may be due to its antioxidant, free radical scavenging, and amelioration of inflammatory response along with elevation of antioxidant defense system.

\section{CONCLUSION}

In conclusion, exposure with DEN clearly induced liver tumour formation. MEIL treatment ameliorated the level of hepatic injury in DEN treated animals. Our findings recommended that MEIL was effective in the treatment of chemically induced liver tumours in rats. The anticancer and chemopreventive mechanisms that involved in the inhibition of HCC contained the down-regulation of free radicals via antioxidant defense mechanism as well as suppression of inflammatory mediators involved in carcinogenesis. These findings were of great importance for the discovery and development of new and safe drugs for the treatment of liver cancer. 
Financial support and sponsorship: Nil.

Conflict of Interests: There are no conflicts of interest.

\section{REFERENCES}

Aggarwal BB, Shishodia S. 2006. Molecular targets of dietary agents for prevention and therapy of cancer. Biochem Pharmacol, 2006; 71: 1397-1421.

Borbath I, Leclercq IA, Sempoux C, Abarca-Quinones J, Desaeger C, Horsmans Y. 2010. Efficacy of lanreotide in preventing the occurrence of chemically induced hepatocellular carcinoma in rats. Chem Biol Interact, 2010; 183: 238-48.

Burton ER, Libutti SK. Targeting TNF-alpha for cancer therapy. J Biol, 2009; 8: 85.

Burton K. A study of the conditions and mechanism of the diphenylamine reaction for the colorimetric estimation of deoxyribonucleic acid. Biochem J, 1956; 62: 315-23.

Chen B, Ning M, Yang G. Effect of paeonol on antioxidant and immune regulatory activity in hepatocellular carcinoma rats. Molecules, 2012; 17: 4672-83.

Devasagayam TP, Tarachand U. Decreased lipid peroxidation in the rat kidney during gestation. Biochem Biophys Res Commun, 1987; 145: 134-38.

Dhanasekaran M, Baskar AA, Ignacimuthu S, Agastian P, Duraipandiyan V. Chemopreventive potential of Epoxy clerodane diterpene from Tinospora cordifolia against diethylnitrosamine-induced hepatocellular carcinoma. Invest New Drugs, 2009; 27: 347-55.

El Miniawy HMF, Ahmed KA, Tony MA, Mansour SA, Khattab MMS. Camel milk inhibits murine hepatic carcinogenesis, initiated by diethylnitrosamine and promoted by phenobarbitone. Int J Vet Sci Med, 2014; 2: 136-41.

El-Serag HB, Rudolph KL. Hepatocellular carcinoma: epidemiology and molecular carcinogenesis. Gastroenterology, 2007; 132: 2557-76.

Fotsis T, Pepper MS, Aktas E, Breit S, Rasku S, Adlercreutz H, Wähälä K, Montesano R, Schweigerer L. Flavonoids, dietary-derived inhibitors of cell proliferation and in vitro angiogenesis. Cancer Res, 1997; 57: 2916-21

Ghosh D, Choudhury ST, Ghosh S, Mandal AK, Sarkar S, Ghosh A, Saha KD, Das N. Nanocapsulated curcumin: oral chemopreventive formulation against diethylnitrosamine induced hepatocellular carcinoma in rat. Chem Biol Interact, 2012; 195: 206-14.

Glory DM, Thiruvengadam D. Potential chemopreventive role chrysin against $\mathrm{n}$-nitrosdiethylamine - induced hepatocellular carcinoma in rats. Biomed Prev Nutr, 2012; 2: 106-12.

Habig WH, Pabst MJ, Jakoby WB. Glutathione S-transferases. The first enzymatic step in mercapturic acid formation. J Biol Chem, 1974; 249: 7130-39.

Hemalatha S, Subramanian N, Ravichandran V, Chinnaswamy $\mathrm{K}$. Wound healing activity of Indigofera enneaphylla Linn. Indian J Pharm Sci, 2001; 63: 331-33.

Jagadeesh MC, Sreepriya M, Bali G, Manjulakumari D. Biochemical studies on the effect of curcumin and embelin during $\mathrm{N}$ nitrosodiethylamine/phenobarbital induced-hepatocarcinogenesis in wistar rats. Afr J Biotechnol, 2009; 8: 4618-22.

Jagan S, Ramakrishnan G, Anandakumar P, Kamaraj S, Devaki T. Antiproliferative potential of gallic acid against diethylnitrosamineinduced rat hepatocellular carcinoma. Mol Cell Biochem, 2008; 319: 51-9.

Jemal A, Bray F, Center MM, Ferlay J, Ward E, Forman D. Global cancer statistics. CA Cancer J Clin, 2011; 61: 69-90.

Kintzios SE. Terrestrial plant-derived anticancer agents and plant species used in anticancer research. Crit Rev Plant Sci, 2006; 25: $79-113$.

Knockaert M, Blondel M, Bach S, Leost M, Elbi C, Hager GL, Nagy SR, Han D, Denison M, Ffrench M, Ryan XP, Magiatis P, Polychronopoulos P, Greengard P, Skaltsounis L, Meijer L. Independent actions on cyclin-dependent kinases and aryl hydrocarbon receptor mediate the antiproliferative effects of indirubins. Oncogene, 2004; 23: 4400-12.

Kumar RS, Rajkapoor B, Perumal P. Antioxidant potential of Indigofera linnaei Ali: an in vitro study. PharmacologyOnline, 2011a; 1: 710-20.

Kumar RS, Rajkapoor B, Perumal P. Antitumor and cytotoxic activities of methanol extract of Indigofera linnaei Ali. Asian Pac J Cancer Prev, 2011b; 12: 613-18.

Kumar RS, Rajkapoor B, Perumal P, Kumar SV, Geetha AS. Beneficial effects of methanolic extract of Indigofera linnaei Ali. on the inflammatory and nociceptive responses in rodent models. Braz J Pharm Sci, 2016; 52: 113-23.

Kumar V, Kato N, Urabe Y, Takahashi A, Muroyama R, Hosono N, Otsuka M, Tateishi R, Omata M, Nakagawa H, Koike K, Kamatani N, Kubo M, Nakamura Y, Matsuda K. Genome-wide association study identifies a susceptibility locus for $\mathrm{HCV}$-induced hepatocellular carcinoma. Nat Genet, 2011; 43: 455-58.

Lowry OH, Rosebrough NJ, Farr AL, Randall RJ. Protein measurement with the Folin phenol reagent. J Biol Chem, 1951; 193: $265-$ 75 .

Luo H, Jiang BH, King SM, Chen YC. Inhibition of cell growth and VEGF expression in ovarian cancer cells by flavonoids. Nutr Cancer, 2008; 60: 800-9.

Majak W, Benn M, McEwan D, Pass MA. Three nitropropanoyl esters of glucose from Indigofera linnaei. Phytochemistry, 1992; 31: 239395.

Man S, Gao W, Zhang Y, Huang L, Liu C. Chemical study and medical application of saponins as anti-cancer agents. Fitoterapia, 2010; 81: 703-14.

Mandal AK, Das S, Mitra M, Chakrabarti RN, Chatterjee M, Das N. Vesicular flavonoid in combating diethylnitrosamine induced hepatocarcinoma in rat model. J Exp Ther Oncol, 2008; 7: 123-33.

Marklund S, Marklund G. Involvement of the superoxide anion radical in the autoxidation of pyrogallol and a convenient assay for superoxide dismutase. Eur J Biochem, 1974; 47: 469-74.

Middleton E Jr, Kandaswami C, Theoharides TC. The effects of plant flavonoids on mammalian cells: implications for inflammation, heart disease, and cancer. Pharmacol Rev, 2000; 52: 673-751.

Mittal G, Brar AP, Soni G. Impact of hypercholesterolemia on toxicity of $\mathrm{N}$-nitrosodiethylamine: biochemical and histopathological effects. Pharmacol Rep, 2006; 58: 413-19.

Oak MH, El Bedoui J, Schini-Kerth VB. Antiangiogenic properties of natural polyphenols from red wine and green tea. J Nutr Biochem, 2005; 16: 1-8.

Park DH, Shin JW, Park SK, Seo JN, Li L, Jang JJ, Lee MJ. Diethylnitrosamine (DEN) induces irreversible hepatocellular carcinogenesis through overexpression of G1/S-phase regulatory proteins in rat. Toxicol Lett. 2009; 191: 321-26.

Pracheta P, Sharma V, Singh L, Paliwal R, Sharma S, Yadav S, Sharma S. Chemopreventive effect of hydroethanolic extract of Euphorbia neriifolia leaves against DENA-induced renal carcinogenesis in mice. Asian Pac J Cancer Prev, 2011; 12: 677-83.

Rajendraprasad Y, Chakradhar V. A new isoflavone from Indigofera linnaei. Indian J Chem, 2004; 43B: 1807-8.

Rajkapoor B, Murugesh N, Chodon D, Sakthisekaran D. Chemoprevention of N-nitrosodiethylamine induced phenobarbitol promoted liver tumors in rat by extract of Indigofera aspalathoides. Biol Pharm Bull, 2005; 28: 364-66.

Ramakrishnan G, Augustine TA, Jagan S, Vinodhkumar R, Devaki T. Effect of silymarin on $\mathrm{N}$-nitrosodiethylamine induced hepatocarcinogenesis in rats. Exp Oncol, 2007; 29: 39-44.

Ravindranath MH, Ramasamy V, Moon S, Ruiz C, Muthugounder S. Differential growth suppression of human melanoma cells by tea (Camellia sinensis) epicatechins (ECG, EGC and EGCG). Evid Based Complement Alternat Med, 2009; 6: 523-30.

Rotruck JT, Pope AL, Ganther HE, Swanson AB, Hafeman DG, Hoekstra WG. Selenium: biochemical role as a component of glutathione peroxidase. Science, 1973; 179: 588-90 
Roy SR, Gadad PC. Effect of $\beta$-asarone on diethylnitrosamineinduced hepatocellular carcinoma in rats. Indian J Health Sci, 2016; 9: 828.

Schinder WC.1957. Determination of nucleic acid in tissue by pentose analysis: Methods in Enzymology. In: Colowick SP and Kaplon NO, ed. New York: Academic Press Vol. III, 680-84.

Sell S, Leffert HL. Liver cancer stem cells. J Clin Oncol, 2008; 26: $2800-05$

Shih WL, Yu MW, Chen PJ, Wu TW, Lin CL, Liu CJ, Lin SM, Tai DI, Lee SD, Liaw YF. Evidence for association with hepatocellular carcinoma at the PAPSS1 locus on chromosome 4q25 in a family-based study. Eur J Hum Genet, 2009; 17: 1250-59.

Singh BN, Singh BR, Sharma BK, Singh HB. Potential chemoprevention of $\mathrm{N}$-nitrosodiethylamine-induced hepatocarcinogenesis by polyphenolics from Acacia nilotica bark. Chem Biol Interact, 2009; 181: 20-28.

Singh JP, Selvendiran K, Banu SM, Padmavathi R, Sakthisekaran D. Protective role of Apigenin on the status of lipid peroxidation and antioxidant defense against hepatocarcinogenesis in Wistar albino rats. Phytomedicine, 2004; 11: 309-14.

Sinha AK. Colorimetric assay of catalase. Anal Biochem, 1972; 47: 389-94.

Sivaramakrishnan V, Shilpa PN, Praveen Kumar VR, Niranjali Devaraj S. Attenuation of N-nitrosodiethylamine-induced hepatocellular carcinogenesis by a novel flavonol-Morin. Chem Biol Interact, 2008; 171: 79-88.

Sugihara K, Kitamura S, Yamada T, Okayama T, Ohta S, Yamashita K, Yasuda M, Fujii-Kuriyama Y, Saeki K, Matsui S, Matsuda T. Aryl hydrocarbon receptor-mediated induction of microsomal drugmetabolizing enzyme activity by indirubin and indigo. Biochem. Biophys Res Commun, 2004; 318: 571-78.

Taha MM, Abdul AB, Abdullah R, Ibrahim TA, Abdelwahab SI, Mohan S. Potential chemoprevention of diethylnitrosamine-initiated and 2-acetylaminofluorene-promoted hepatocarcinogenesis by zerumbone from the rhizomes of the subtropical ginger (Zingiber zerumbet). Chem Biol Interact, 2010; 186: 295-305.

Toyoda H, Kumada T, Tada T, Sone Y, Kaneoka Y, Maeda A. Tumor Markers for Hepatocellular Carcinoma: Simple and Significant Predictors of Outcome in Patients with HCC. Liver Cancer, 2015; 4: 12636.

Weber G, Shen F, Prajda N, Yeh YA, Yang H, Herenyiova M, Look KY. Increased signal transduction activity and down-regulation in human cancer cells. Anticancer Res, 1996; 16: 3271-82.

Wills PJ, Suresh V, Arun M, Asha VV. Antiangiogenic effect of Lygodium flexuosum against $\mathrm{N}$-nitrosodiethylamine-induced hepatotoxicity in rats. Chem Biol Interact, 2006; 164: 25-38.

Yadav AS, Bhatnagar D. Chemo-preventive effect of Star anise in N-nitrosodiethylamine initiated and phenobarbital promoted hepatocarcinogenesis. Chem Biol Interact, 2007; 169: 207-14.

Yang YY. Can serum cytokines predict hepatic cytokine expression in liver cirrhosis? J Chin Med Assoc, 2011; 74: 485-86.

Zaghloul SG, Khalifa NA, Assal NM. Angiogenin and vascular endothelial growth factor in hepatocellular carcinoma in correlation with tumour vascularity and pathological differentiation. Arab J Gastroenterol, 2006; 7: 9-13.

\section{How to cite this article:}

Kumar RS, Kumar SV, Rajkapoor B, Pravin N, Mahendiran D. Chemopreventive effect of Indigofera linnaei extract against diethylnitrosamine induced hepatocarcinogenesis in rats. J App Pharm Sci, 2016; 6 (11): 199-209. 